\title{
Loss of Control over Addictive Behaviors Mediate the Effect of Social Exclusion in Addiction
}

\author{
Takuto Yoshida ${ }^{1} \&$ Mitsuhiro Ura ${ }^{2}$ \\ ${ }^{1}$ Graduate School of Psychology, Otemon Gakuin University, 2-1-15 Nishiai, Ibaraki City, Osaka 567-8502 Japan \\ ${ }^{2}$ Otemon Gakuin University, 2-1-15 Nishiai, Ibaraki City, Osaka 567-8502 Japan \\ Correspondence: Takuto Yoshida, Graduate School of Psychology, Otemon Gakuin University, 2-1-15 Nishiai, \\ Ibaraki City, Osaka 567-8502 Japan.
}

Received: December 16, 2020

Accepted: February 2, 2021

Online Published: February 9, 2021

doi:10.5539/ijps.v13n1p27

URL: https://doi.org/10.5539/ijps.v13n1p27

\begin{abstract}
Previous research suggests that a lack of social connections predicts increased addiction-related problems, and that loss of control mediates this relationship. However, this mediation effect is inconsistent and depends on the type of addiction. We investigated if the loss of control mediated the relationship between low social connections and addiction, by integrating different addictive behaviors. Our results demonstrated that experiences of exclusion from others and rejection from society predicted a higher degree of addiction-related problems Integrating and analyzing different addictions demonstrate the mediation effect of loss of control over addiction. These results suggest that the mediation effects of loss of control between low social connection and addiction-related problems are observed when addictive behaviors are integrated. Our findings can suggest that the loss of control of addictive behaviors is the necessary factor to predict addiction-related problems by low social connection.
\end{abstract}

Keywords: addiction, addiction-related problem, social exclusion, control, mediation effect

\section{Introduction}

People indulge in different behaviors that result in addiction. We defined behaviors resulting in addiction as addictive behaviors. It is known that alcohol and drug use is addictive to humans and animals. Recently, addiction without substance use has also become a problem, and gambling addiction, shopping addiction, internet addiction, social media addiction, and gaming addiction have been identified and associated with social problems.

Addiction is defined as a situation in which an originally adaptive behavior no longer fits or benefits an individual because of repeating the behavior without appropriate self-control (Saito, 1984). "Dependence" is similar to addiction; the former is defined as a pathological situation of physical and/or psychological dependence through continuous legal or illegal drug use (Babor, Higgins-Biddle, Saunders, \& Monteiro, 2001). Although some confusion exists between addiction and dependence among Japanese researchers, "dependence" tends to be used concerning substance use, whereas "addiction" tends to be used in situations not limited to substance use (Takahashi, Hironaka, \& Shimazaki, 2012). We operationally defined addiction as a situation in which social and/or psychological problems are experienced because of being absorbed in a specific behavior. In this study, we used "addiction" rather than "dependence" because we did not focus on drug use. At first, addictive behaviors are adaptive, and most people conduct addictive behaviors without encountering problems because they maintain control over the behavior. However, continuing the addictive behavior without any control could result in the loss of benefits to the individual and lead to difficulties in their social life. Moreover, specific people develop addiction problems because of the lack of control. Addiction related problems might arise through the mediation of losing control of addictive behaviors. Therefore, loss of control is a crucial factor in predicting addiction. Identifying factors increasing social problems caused by addictive behaviors and factors decreasing the control of addictive behaviors could help people maintain addictive behaviors without addiction problems.

A measure of addiction that can distinguish factors leading to loss of control of addictive behavior from other problems caused by loss of control, based on the above definition of addiction, would be desirable. A measure of 
addiction that can separate the loss of control factor from other factors should assess addictive behaviors in general, rather than separately assessing specific addictive behaviors. Studies on behavioral addiction that are not limited to substance use are at an early stage. Many scales have been developed for assessing individual addictive behaviors, and some of them specialize in assessing the use of specific drugs. For example, a scale has been developed to assess and screen addiction to alcohol (Babor, Higgins-Biddle, Saunders, \& Monteiro, 2001), whereas another scale has been developed to assess and screen addiction to drugs other than alcohol (Skinner, 1982). Also, different scales specialize in assessing behaviors unrelated to substance use. For example, each scale assesses and screens addiction to gambling behavior (Lesieur \& Blume, 1987), to eating behavior (Gearhardt, Corbin, \& Brownell, 2016), to smartphone using behavior (Kwon et al., 2013). On the other hand, only a few general scales can assess any type of addictive behavior. One such scale, developed by Ishida (2010), assesses the degree of addiction to different kinds of behaviors, including hobbies, if addictive behaviors are controlled. Significantly, Ishida (2010) 's scale distinguishes factors related to loss of control of addictive behaviors. In this scale, participants select specific addictive behaviors they usually conduct from multiple behaviors when responding to this scale. The scale assesses the degree of addiction by separating them into three factors: "Negative influences on interpersonal relationships and social life," "Feelings of indispensability," and the "Loss of control." We used Ishida (2010) 's scale in this study because this study did not focus on addictive behaviors in general rather than individual addictive behaviors.

Addictive behaviors that are legal and controllable can be adaptive. However, some people cannot control addictive behaviors, and they develop problems due to losing control of their addictive behavior. Identifying factors that reduce problem behaviors in people with and without control of their addiction, including variables that increase addiction and decrease the control of addictive behaviors, could help prevent problems associated with addiction. Prior research has indicated that poor social connections and social rejection correlate with the loss of control of addictive behaviors. The lack of social connections that are known to increase the loss of control related to addictive behaviors, are correlated with addiction severity, as suggested by several studies. For example, increased loneliness predicts gambling addiction severity (McQuade \& Gill, 2012) and higher Internet gaming disorder diagnostic scores (Sarda, B'egue, Bry, \& Gentile, 2016). Moreover, participants thinking about the future spent alone selected high-risk choices in a gambling task (Twenge, Catanese, \& Baumeister, 2002). Though focusing on self-destructive behaviors, this suggests that loneliness influences addictive behaviors such as gambling.

The relationship between lack of social connections and addiction might be explained by Self-regulation, which is defined as an individual's capacity to alter their behaviors for conforming with their social group (Baumeister, DeWall, Ciarocco, \& Twenge, 2005). The lack of social connections might increase addiction by decreasing self-regulation, which might foster and increase addictive behaviors. The study, which did not specifically focus on addition, nevertheless suggests that stimulating social exclusion by thinking about the future spent alone decreases self-regulation, which reduces heath promoting behaviors and increases health-harming behaviors. Among the few studies that have directly focused on addictive behaviors, a study investigated internet addiction and indicated that loneliness predicts higher addiction and lower self-control, which was mediated by loneliness (Özdemir, Kuzucu, \& Ak, 2014). The other study suggested that loneliness directly predicts gambling addiction severity, but self-regulation does not mediate the relationship between addiction and self-regulation (McQuade \& Gill, 2012). These studies indicate that the mediation effects of self-regulation on addictive behavior is inconsistent and depends on the type of addictive behavior. Therefore, we integrated different types of addictive behaviors and examined if the control of addictive behaviors mediated between the lack of social connections exemplified by social exclusion and addiction-related problems.

\section{Purpose}

The purpose of the present study is to consider the hypothesis that though the higher experience of social exclusion predicts the higher degree of problems about addictive behaviors, the loss of control about addictive behaviors mediates this prediction. Though previous studies focused on the lack of social connection on the low connection of other people such as loneliness and social exclusion from others, the low social connection has another point. Social connection can include the connection between social systems. Thus, the present study added an indicator of the experience of rejection from social systems. Because previous studies have not focused on the effect of low social connection of social systems, this studied analyzed and considered the effect of social exclusion from others and rejection from social systems separately. 


\section{Method}

\subsection{Participants}

Participants were Japanese adults $(\mathrm{N}=700350$ men and 350 women, mean age $46.62 S D=11.65)$, who were registered with Rakuten Insight, Inc., which is an internet research company. Of these, the data of 603 participants (283 men and 320 women, mean age $46.09, S D=11.52)$ were analyzed after excluding participants who had missing values, or who selected "other behaviors" in the addictive behavior option.

\subsection{Questionnaires}

The participants completed the Addiction Tendency Scale (Ishida, 2010), the Scale of Social Exclusion Experience, and satisfice detection items.

\subsection{Addiction Tendency Scale}

This questionnaire, which was developed by Ishida (2010), consists of three factors: "Bad influence on interpersonal relationships and social life" (ABIOIRSL) consisting of 9 items; "Feelings of indispensability" (AFOI) consisting of 10 items; "Loss of control" (ALOC) consisting of 12 items. Participants select their preferred behaviors in everyday life from 12 behaviors: shopping, sex, drinking, smoking, working, eating, losing weight, surfing the internet, social media use, offline gaming, and online gaming. Responses to this scale are made on a five-point Likert scale.

\subsection{Questionnaire of Socially Excluded Experience}

This questionnaire was developed by referring to Yanagisawa, Isobe, \& Ura (2010)'s study. The original questionnaire consisted of a two-factor structure, "Experience of exclusion from others" (EOEFO) consisting of 11 items, and "Experience of acceptance from others" consisting of 6 items. This study included a new factor named "Experience of rejection from social systems" (EORFSS) consisting of six items to this questionnaire and developed a new questionnaire. EOEFO and EORFSS were used in the factor analysis and other analyses because we only focused on the experience of social exclusion. The responses to this questionnaire are made on a five-point Likert scale.

\subsection{Items for Detecting Satisfaction}

The item in the Addiction Tendency Scale for assessing satisfaction stated, "You have to answer 'the leftmost' choice" which was a satisfice detection item which stated, "You have to answer "the rightmost' choice" in the tendency scale of experiences of social exclusion. Any responses that did not follow this instruction were excluded from the analysis.

\section{Results}

\subsection{Factor Analysis}

We confirmed the factor structure of the new questionnaire developed by including a new factor named EORFSS to the scale of Yanagisawa, Isobe, \& Ura (2010)'s study. Then we conducted exploratory factor analysis using the maximum likelihood method and Promax rotation on the 16 items of the scale for assessing social exclusion experiences. We assumed a three-factor structure based on theoretical perspectives and screen plots. The results indicated adequate fitness of the factor structures $(\mathrm{CFI}=.95, \mathrm{RMSEA}=.07)$.

\subsection{Basic Statistics}

The number of participants that chose each addictive behavior were $68,10,59,15,45,49,147,11,102,44,21$, 21 for shopping, sex, drinking, gambling, smoking, working, eating, losing weight, surfing the internet, social media using, offline gaming, and online gaming respectively (see Table 1). Basic statistics (mean, SD, alpha coefficient) of the Addiction Tendency Scale and the Questionnaire of Socially Excluded Experience are shown in Table 2. 
Table 1. The number of addictive behavior respondents

\begin{tabular}{ll}
\hline Addictive Behavior & Respondents \\
\hline Drinking & 59 \\
Eating & 147 \\
Gambling & 15 \\
Internet Surfing & 102 \\
Losing Weight & 11 \\
Offline Gaming & 21 \\
Online Gaming & 32 \\
Sexual Behavior & 10 \\
Shopping & 68 \\
Smoking & 45 \\
Social Media Using & 44 \\
Working & 49
\end{tabular}

Table 2. Basic Statistics about each factor

\begin{tabular}{llll}
\hline Variable & Mean & SD & raw_alpha \\
\hline ALOC & 2.47 & .93 & .91 \\
AFOI & 2.99 & 1.07 & .92 \\
ABIOIRSL & 2.02 & .83 & .87 \\
EOEFO & 1.92 & .72 & .90 \\
EOROFSS & 2.28 & .85 & .85 \\
\hline
\end{tabular}

\subsection{Correlations}

We analyzed correlations between each Addiction Tendency Scale factor score and each Questionnaire of Experiences of Socially Excluded factor score (see Table3).

Table 3. Correlations of each factor

\begin{tabular}{|c|c|c|c|c|}
\hline & 1 & 2 & 3 & 4 \\
\hline 1.ALOC & & & & \\
\hline 2.ABIOIRSL & $.71 * *$ & & & \\
\hline 3.AFOI & $.59 * *$ & $.44 * *$ & & \\
\hline 4.EOEFO & $.36^{* *}$ & $.48 * *$ & $.16^{* *}$ & \\
\hline 5.EORFSS & $.37 * *$ & $.37 * *$ & $.19 * *$ & $.57 * *$ \\
\hline
\end{tabular}

$* p<.05, * * p<.01$

4.4 Mediation Analysis

The mediation analysis is shown in Figure 1. The squares in Figure 1 represent the observation variable. Moreover, each "EOSE" variable represents a single factor in the Experience of Socially Excluded Scale, EOEFO (Experience of Exclusion from Others), or EORFSS (Experience of Rejection from Social Systems). The $\mathrm{a}, \mathrm{b}, \mathrm{c}, \mathrm{d}$, and e paths respectively represent the direct effect from EOSE to ABIOIRSL, the direct effect from EOSE to AFOI, the direct effect from EOSE to ALOC, the direct effect from ALOC to ABIORSL, and the direct effect ALOC to AFOI. The indirect effect from EOSE to ABIOIRSL, the indirect effect from EOSE to AFOI, the total effect from EOSE to ABIOIRSL, and the total effect from EOSE to AFOI can be expressed as follows: (1), (2), (3), and (4).

$$
\begin{aligned}
& c d \\
& c e \\
& a+c d \\
& b+c e
\end{aligned}
$$




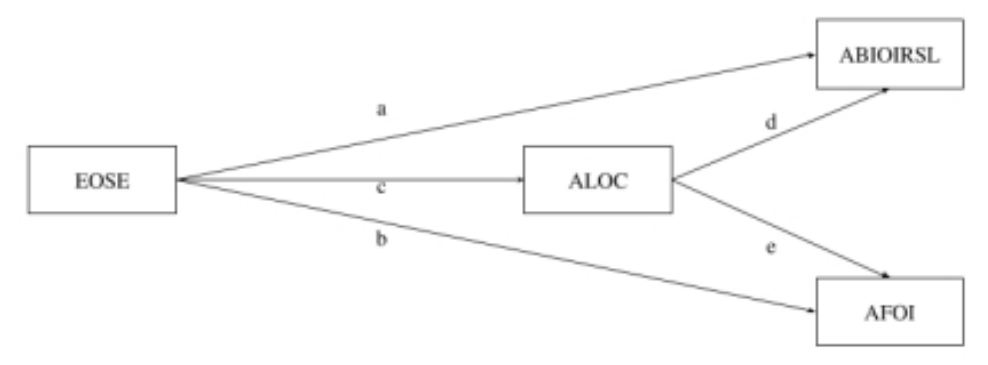

Figure 1

The fit value of the model, including the Chi-square value ( $p$-value), CFI, and RMSEA of EOEFO as EOSE were respectively 2.02 (.16), 1.00 , and .04 , and the fit value of the model, including the Chi-square value ( $p$-value), CFI, and RMSEA of EORFSS as EOSE were .81 (.37), 1.00 , and .00 respectively.

Tables 4 and 5 show the estimated standardized coefficients of each path, the $p$-value of the path, and the upper and lower confidence interval values of each model. The result of the mediation analysis indicated partial mediation effects of ALOC on ABIOIRSL for EOEFO (.22) and EORFSS (.25), whereas there was a full mediation effect of ALOC on AFOI for EOEFO (.22) and EORFSS (.23).

Table 4. The model of EOEFO as EOSE

\begin{tabular}{llllll}
\hline path & the effect of path & $\begin{array}{l}\text { estimated standardized } \\
\text { regression coefficient }\end{array}$ & & ci.lower & ci.upper \\
\hline $\mathrm{a}$ & Direct Effect from EOEFO to ABIOIRSL & .25 & $* *$ & .20 & .31 \\
$\mathrm{~b}$ & Direct Effect from EOEFO to AFOI & -.06 & & -.13 & .01 \\
$\mathrm{c}$ & Effect from EOEFO to ALOC & .36 & $* *$ & .29 & .43 \\
$\mathrm{~d}$ & Effect from ALOC to ABIOIRSL & .62 & $* *$ & .57 & .67 \\
$\mathrm{e}$ & Effect from ALOC to AFOI & .62 & $* *$ & .56 & .67 \\
$\mathrm{~cd}$ & Indirect Effect to ABIOIRSL & .22 & $* *$ & .18 & .27 \\
$\mathrm{a}+\mathrm{cd}$ & Total Effect to ABIOIRSL & .48 & $* *$ & .42 & .53 \\
$\mathrm{ce}$ & Indirect Effect to AFOI & .22 & $* *$ & .18 & .27 \\
$\mathrm{~b}+\mathrm{ce}$ & Total Effect to AFOI & .16 & $* *$ & .08 & .24 \\
\hline
\end{tabular}

$* p<.05, * * p<.01$

Table 5. The model of EORFSS as EOSE

\begin{tabular}{llllll}
\hline path & the effect of path & $\begin{array}{l}\text { estimated standardized } \\
\text { regression coefficient }\end{array}$ & & ci.lower & ci.upper \\
\hline $\mathrm{a}$ & Direct Effect from EORFSS to ABIOIRSL & .12 & $* *$ & .06 & .18 \\
$\mathrm{~b}$ & Direct Effect from EORFSS to AFOI & -.03 & -.10 & .03 \\
$\mathrm{c}$ & Effect from EORFSS to ALOC & .37 & $* *$ & .31 & .44 \\
$\mathrm{~d}$ & Effect from ALOC to ABIOIRSL & .67 & $* *$ & .62 & .71 \\
$\mathrm{e}$ & Effect from ALOC to AFOI & .61 & $* *$ & .55 & .66 \\
$\mathrm{~cd}$ & Indirect Effect to ABIOIRSL & .25 & $* *$ & .20 & .30 \\
$\mathrm{a}+\mathrm{cd}$ & Total Effect to ABIOIRSL & .37 & $* *$ & .30 & .43 \\
$\mathrm{ce}$ & Indirect Effect to AFOI & .23 & $* *$ & .18 & .27 \\
$\mathrm{~b}+\mathrm{ce}$ & Total Effect to AFOI & .19 & $* *$ & .11 & .27 \\
\hline
\end{tabular}

$* p<.05, * * p<.01$ 


\section{Discussion}

Our results demonstrated that the control of addictive behaviors mediates the effects of social exclusion to addiction-related problems.

The mediation effects of control of addictive behaviors are confirmed between the experience of rejection from social systems and addiction-related problems, and between the experience of social exclusion from others and addiction-related problems. This finding may imply that the effect of the experience of rejection from social systems on addiction-related problems is equivalent to the effect of the experience of social exclusion from others even through the mediation effect of control. From some previous studies (Cole, Logan, \& Walker, 2011; March, Oviedo-Joekes, \& Romero, 2006), it is assumed that the experience of social exclusion that influences addiction includes not only the exclusion received from others, but also the experience of being rejected from the social systems.

Though the mediating effects of control of addictive behaviors are observed, control of addictive behaviors had the full mediation effect from the social excluded experience to the "feelings of indispensability" factor of addiction-related problems, in contrast, control of addictive behaviors had the partial mediation effect from the social excluded experience to the "bad influence of interpersonal relationships and social life" factor of addiction-related problems. This difference in mediation effects of social exclusion experience on different addiction problems might be explained by the correlation between each addiction problem and low social connections. The "feelings of indispensability" factor in the Addiction Tendency Scale is an independent concept from low social connections. Therefore, the direct effect of each exclusion experience from others and rejection from the social system on feelings of addictive behaviors' indispensability might have disappeared because of the mediation effect of loss of control. On the other hand, the "bad influence of interpersonal relationships and social life" factor in Addiction Tendency Scale was not an independent concept from low social connections. Therefore, the direct effects of each exclusion experience from others and rejection from social systems on negative influence on interpersonal relationships and social life by addictive behaviors might have remained after the mediation effect of loss of control.

The present study had a limitation. This study was a cross-sectional questionnaire study, which was not designed to investigate temporal causality. Nevertheless, this study suggested a mediation relationship. It is necessary for future studies to investigate the temporal causality through experimental studies.

The present study was the first study to integrate many different addictive behaviors. The results suggest that the social exclusion experience predicts more problems related to addictive behaviors, and loss of control of addictive behaviors mediates this relationship. These findings are useful for future researchers examining factors that increase the loss of control of addictive behaviors. It is expected that such studies would help prevent addiction-related problems.

\section{Reference}

Babor, T. F., Higgins-Biddle, J. C., Saunders, J. B., \& Monteiro, M. G. (2001). The Alcohol Use Disorders Identification Test. Guidelines for Use in Primary Care (2nd ed.). Geneva: World Health Organization, Department of Mental Health; Substance Dependence.

Baumeister, R. F., DeWall, C. N., Ciarocco, N. J., \& Twenge, J. M. (2005). Social exclusion impairs self-regulation. Journal of Personality and Social Psychology, 88(4), 589-604. https://doi.org/10.1037/0022-3514.88.4.589

Cole, J., Logan, T. K., \& Walker, R. (2011). Social exclusion, personal control, self-regulation, and stress among substance abuse treatment clients. Drug and Alcohol Dependence, 113(1), 13-20. https://doi.org/10.1016/j.drugalcdep.2010.06.018

Gearhardt, A. N., Corbin, W. R., \& Brownell, K. D. (2016). Development of the Yale Food Addiction Scale Version 2.0. Psychology of Addictive Behaviors, 30(1), 113-121. https://doi.org/10.1037/adb0000136

Ishida, T. (2010). Constructing an addiction tendency scale for adolescents (In Japanese with English abstract). Kyushu University psychological research, 11, 91-99. https://doi.org/10.15017/18449

Kwon, M., Lee, J.-Y., Won, W.-Y., Park, J.-W., Min, J.-A., Hahn, C., ... Kim, D.-J. (2013). Development and Validation of a Smartphone Addiction Scale (SAS). PLoS ONE, 8(2), e56936. https://doi.org/10.1371/journal.pone.0056936

Lesieur, H. R., \& Blume, S. B. (1987). The South Oaks Gambling Screen (SOGS): A new instrument for the identification of Pathological gamblers. American Journal of Psychiatry, 144(9), 1184-1188. 
https://doi.org/10.1176/ajp.144.9.1184

March, J. C., Oviedo-Joekes, E., \& Romero, M. (2006). Drugs and Social Exclusion in Ten European Cities. European Addiction Research, 12(1), 33-41. https://doi.org/10.1159/000088581

McQuade, A., \& Gill, P. (2012). The role of loneliness and self-control in predicting problem gambling behaviour. Gambling Research: Journal of the National Association for Gambling Studies (Australia), 24(1), 18.

Özdemir, Y., Kuzucu, Y., \& Ak, Ş. (2014). Depression, loneliness and Internet addiction: How important is low self-control? Computers in Human Behavior, 34, 284-290. https://doi.org/10.1016/j.chb.2014.02.009

Saito, M. (1984). Addictive behaviors and family recoverying from overeating and alcoholism $\sim$ (In Japanese, translated by the author of this article). Tokyo: Yuhikaku.

Sarda, E., B'egue, L., Bry, C., \& Gentile, D. (2016). Internet Gaming Disorder and Well-Being: A Scale Validation. Cyberpsychology, Behavior, and Social Networking, 19(11), 674-679. https://doi.org/10.1089/cyber.2016.0286

Skinner, H. A. (1982). The drug abuse screening test. Addictive Behaviors, 7(4), 363-371. https://doi.org/10.1016/0306-4603(82)90005-3

Takahashi, N., Hironaka, N., \& Shimazaki, T. (2012). The relationship between relevant terms of dependence in Japan: The bibliometric analysis of article titles and keywords (In Japanese with English abstract). Japanese Association of Behavioral Science, 51(1), 25-35. Retrieved from https://ci.nii.ac.jp/naid/40019488323/

Twenge, J. M., Catanese, K. R., \& Baumeister, R. F. (2002). Social exclusion causes self-defeating behavior. Journal of Personality and Social Psychology, 83(3), 606-615. https://doi.org/10.1037/0022-3514.83.3.606

Yanagisawa, K., Isobe, C., \& Ura, M. (2010). The influence of past experiences of social exclusion and trait self-esteem on social pain and future interpersonal relationships (In Japanese, translated by the author of this article.). Proceedings of the 57th annual conference of the Japanese Group Dynamics Association.

\section{Copyrights}

Copyright for this article is retained by the author(s), with first publication rights granted to the journal.

This is an open-access article distributed under the terms and conditions of the Creative Commons Attribution license (http://creativecommons.org/licenses/by/4.0/). 